\title{
Obevisto
}

AS DUAS FACES DO

\section{SEXISMO NA MÍDIA:}

como Marcela Temer e

Dilma Rousseff (PT) são

retratadas pela Veja e

IstoÉ
SEXIST DOUBLE STANDARD IN

MEDIA: how Marcela Temer and

Dilma Rousseff (PT) are

portrayed in Veja Magazine and IstoÉ Magazine

LAS DOS CARAS DEL SEXISMO MIDIÁTICO: cómo Marcela Temer e Dilma Rousseff son retratadas por las revistas Veja e IstoÉ

\section{Ana Maria Conceição Veloso ${ }^{1}$ \\ Fabíola Mendonça de Vasconcelos ${ }^{2}$ \\ Laís Ferreira ${ }^{3,4}$}

\section{RESUMO}

A forma como a mídia brasileira retrata a mulher no campo político é um dos aportes deste artigo, que analisa as reportagens de duas revistas semanais, a Veja e a IstoÉ: enquanto a primeira tenta mostrar uma vice-primeira-dama, Marcela Temer, como "bela, recatada e do lar", a segunda traz uma presidenta

\footnotetext{
${ }^{1}$ Doutora em comunicação pelo Programa de Pós-Graduação em Comunicação (PPGCOM) da Universidade Federal de Pernambuco (UFPE), professora do Departamento de Comunicação da UFPE e pesquisadora do Observatório de Mídia: Gênero, Democracia e Direitos Humanos da UFPE. E-mail: anavelosoufpe@gmail.com.

${ }^{2}$ Doutoranda pelo Programa de Pós-Graduação em Serviço Social da Universidade Federal de Pernambuco (UFPE) e assessora de comunicação do Sindicato dos Servidores Públicos Federais (Sindsep). E-mail: fabiolamendonca@gmail.com.

${ }^{3}$ Mestranda em Comunicação pelo Programa de Pós-Graduação em Comunicação (PPGCOM) da Universidade Federal de Pernambuco (UFPE). E-mail: lais.ferreiraa@gmail.com.

${ }^{4}$ Endereço de contato do autor (por correio): Universidade Federal de Pernambuco. Programa de Pós-Graduação em Comunicação. Av. Prof. Moraes Rego, 1235 - Cidade Universitária, Recife PE, Brasil. CEP: 50670-901.
} 


\section{Observatório \\ ISSN n² 2447-4266 \\ Vol. 3, n. 1, Janeiro-Março. 2017 \\ DOI: http://dx.doi.org/10.20873/uft.2447-4266.2017v3n1p58}

da República, Dilma Rousseff, histérica, destemperada, cuja manchete de capa é "As explosões nervosas da presidente". As duas edições são veiculadas no contexto da votação do impeachment da presidenta Dilma Rousseff (PT), votado na Câmara Federal em abril de 2016 e, no Senado, em maio e em agosto do mesmo ano. Utilizando como referenciais teóricos a Economia Política da Comunicação, o trabalho mostra o caráter patriarcal, misógino e preconceituoso das publicações, que reproduzem valores consoantes a formações ideológicas sexistas.

PALAVRAS-CHAVE: Mídia; Economia Política da Comunicação; Dilma Rousseff; Marcela Temer; Sexismo.

\section{ABSTRACT}

This paper aims to show how Brazilian media portrays women in politics. Articles about two public female figures published by Brazilian weekly news magazines, Veja and IstoÉ, were analyzed. While Veja tried to show the Second Lady Marcela Temer as a "beautiful, demure housewife", IstoÉ portrayed the President of the Republic, Dilma Rousseff, as hysterical, intemperate, and published the headline "The nervous explosions of the President". Both editions were published in the context of Dilma Rousseff (PT) impeachment trial. Between April and August 2016, the lower chamber voted for impeachment and the Senate voted to begin the trial, resulting in Rousseff's suspension. Using the Political Economy of Communication as theoretical reference, this paper shows the patriarchal, misogynist and prejudiced character of the magazines, which reproduce sexist ideas.

KEYWORDS: Media; Political Economy of Communications; Dilma Rouseff; Marcela Temer; Sexism.

\section{RESUMEN}

La forma que los medios de comunicación brasileños retratan las mujeres en la política es una de las aportaciones de este artículo, que analiza los temas de portada de dos revistas semanales, Veja y IstoÉ mientras la primera publicación 


\section{Observistotório \\ ISSN n² 2447-4266 \\ Vol. 3, n. 1, Janeiro-Março. 2017 \\ DOI: http://dx.doi.org/10.20873/uft.2447-4266.2017v3n1p58}

intenta mostrar una vice-primera-dama como "hermosa, recatada y el hogar", el segundo periódico aporta una presidenta de la República, Dilma Rousseff, histérica, destemplada, cuyo titular de la capa es "Las explosiones nerviosas de la presidente ". Ambas ediciones datan de antes de la votación de destitución de la presidenta Dilma Rousseff (PT), votada en el Congreso en el més de abril de 2016 y el Senado en mayo y agosto del mismo año. Utilizando referentes teóricos de la economía política de la comunicación, este trabajo muestra el carácter patriarcal, misógino y de prejuicios de las revistas, reproduciendo los valores de formaciones ideológicas sexistas.

PALABRAS CLAVE: Media; Economía Política de la Comunicación; Dilma Rousseff; Marcela Temer; Sexismo.

Recebido em: 22.01.2017. Aceito em: 25.03.2017. Publicado em: 30.03.2017. 


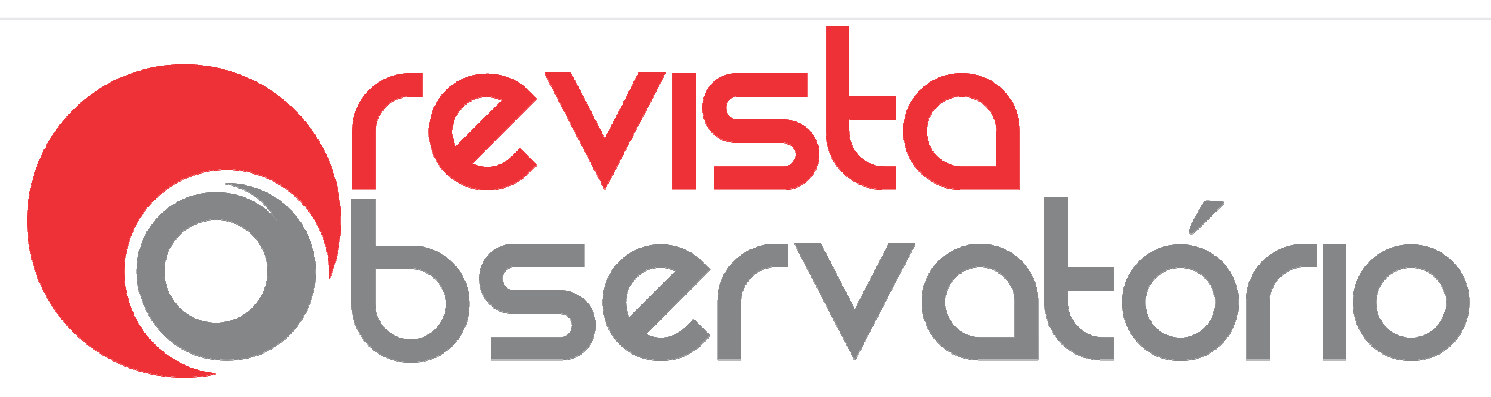

ISSN n² 2447-4266

Vol. 3, n. 1, Janeiro-Março. 2017

DOI: http://dx.doi.org/10.20873/uft.2447-4266.2017v3n1p58

\section{Introdução}

Abril de 2016. Marcela Temer e Dilma Rousseff. Duas mulheres da cena política brasileira estampam as capas e são pautas das principais matérias da Veja e da IstoÉ, revistas semanais de grande circulação no Brasil. Uma é classificada pela Veja como "bela, recatada e do lar" (LINHARES, 2016); a outra, apresentada pela IstoÉ como "sem equilíbrio e condições emocionais de conduzir o país" (PARDELLAS; BERGAMASCO, 2016, p. 32). A primeira, mulher do então vice-presidente Michel Temer, do PMDB. A segunda, presidenta do Brasil, prestes a sofrer o impeachment. Entretanto, o que dois perfis distintos têm em comum quando tratamos da produção jornalística das duas edições? Os traços do sexismo e da misoginia nas suas páginas.

É sabido que, muito mais do que constituir sustentáculos para o exercício do poder pelas elites, os veículos de comunicação podem influenciar a produção mental, uma vez que são também responsáveis pela massificação das ideias de uma época. Estamos tratando de um dos sintomas para o mesmo fato, no qual temos ao menos dois fenômenos que devem ser estudados de modo integrado: (a) a superexposição da imagem e do sexo das mulheres e (b) a invisibilidade feminina no protagonismo das notícias (enquanto fontes). Tais características são denunciadas desde os anos 1980 quando analisamos a relação das mulheres com os meios de comunicação, tendo como referência as constatações do documento da UNESCO, intitulado Un solo mundo, voces múltiples: comunicación e información en nuestro tiempo.

Por supuesto, los medios de comunicación social no son la causa fundamental de la condición subordinada de la mujer. Y no disponen por si solos de medios para subsanarla. Las causas tienen profundas raíces en las estructuras sociales, políticas y económicas así como en actitudes culturalmente determinadas, y sólo se podrá encontrar la solución mediante la introducción de cambios a largo plazo. Sin 


\section{Observatório}

ISSN n² 2447-4266

Vol. 3, n. 1, Janeiro-Março. 2017

DOI: http://dx.doi.org/10.20873/uft.2447-4266.2017v3n1p58

embargo, los medios de comunicación social disponen hasta cierto punto de la facultad de estimular o de retrasar tales cambios (UNESCO, 1988, p. 330-331).

Não obstante, o que os meios de comunicação brasileiros estimulam? O acesso às imagens de um conjunto ou segmento de mulheres despojadas de sua humanidade para emergir, nas telas, páginas, portais e programas de rádio como personificação de um feminino concebido pelo capital e materializado no protagonismo de atrizes e moças "belas, recatadas e do lar", como a personagem da matéria da Veja, que apresentou ao leitor da publicação o perfil de Marcela Temer? Ou a disseminação de que o Brasil tinha uma presidenta "explosiva", "mal-educada" e "fora de si", como retratou a produção da IstoÉ? Temos, aqui, a exposição de duas mulheres diferentes, tratadas de modo similar quando da reprodução de estereótipos que tentam levar o/a leitor/a a formar uma opinião.

Todavia, é preciso destacar que uma parcela da sociedade está atenta aos abusos cometidos pelos meios de comunicação brasileiros contra as mulheres. Uma pesquisa da Fundação Perseu Abramo, sobre hábitos de consumo de mídia da população brasileira, realizada em 2013, revelou que há uma percepção, entre as pessoas ouvidas, de que as mulheres são quase sempre (19\%) ou às vezes (47\%) tratadas com desrespeito pelos meios de comunicação. O levantamento nos leva a observar a perpetuação das violações aos direitos das mulheres pela mídia e a reprodução do sexismo patriarcal, da misoginia e do machismo, em matérias de jornais, de revistas, de rádio e de TV que abusam de narrativas que colocam as mulheres em situações vexatórias e atentam contra os seus direitos.

As reportagens da Veja e da IstoÉ representam muito bem tal tendência, ao expor supostos "desvarios" da presidenta Dilma Rousseff (PT) e ao dar 


\section{Observistotório \\ ISSN n² 2447-4266 \\ Vol. 3, n. 1, Janeiro-Março. 2017}

DOI: http://dx.doi.org/10.20873/uft.2447-4266.2017v3n1p58

visibilidade, em um espaço de grande circulação nacional, a Marcela Temer, "modelo de mulher" que se encaixaria "perfeitamente" nas exigências do lugar histórico que ocupa. Com isso, possuiria os requisitos "indispensáveis" para tal: beleza, maternidade e a submissão à destinação do lar.

\section{Mulheres, esfera pública e a força da Economia Política da Comunicação}

Uma das maiores contribuiç̧̃es que o feminismo, como projeto político e pensamento crítico, trouxe para a humanidade foi o questionamento do modelo patriarcal de construção de sociedade, que destina às mulheres o lugar de coadjuvantes do processo histórico, restringindo a existência da condição feminina à esfera privada. Ao propor uma transformação nas relações de gênero e a igualdade e a liberdade para a mulher, o feminismo a credenciou como sujeito político. Segundo Margareth Rago

É dificil falar de uma epistemologia feminista, sem tocar na discussão sobre os perigos da reafirmação do sujeito "mulher" e de todas as cargas constitutivas dessa identidade no imaginário social. Afinal, [...] É na luta pela visibilidade da "questão feminina", pela conquista e ampliação dos seus direitos específicos, pelo fortalecimento da identidade da mulher, que nasce um contradiscurso feminista e que se constitui um campo feminista do conhecimento. É a partir de uma luta política que nasce uma linguagem feminista (RAGO, 1998, s.p.).

A ruptura de uma identidade socialmente imposta, que limitava o acesso

delas à esfera pública, foi outra conquista do feminismo, como resgata a socióloga Maria Betânia Ávila (2000), ao analisar a produção da filósofa Hanna Arendt: 


\section{Observatório \\ ISSN n² 2447-4266 \\ Vol. 3, n. 1, Janeiro-Março. 2017 \\ DOI: http://dx.doi.org/10.20873/uft.2447-4266.2017v3n1p58}

Penso que, desta forma, se viabiliza o que Arendt (1988) definiu como o direito a ter direitos, uma vez que a conquista dos direitos exige um sujeito que anuncie seu projeto e tenha ação na esfera política, participando, assim, do conflito, que deve ser inerente à democracia e instituindo, como parte desse conflito, a luta contra as desigualdades a que estão sujeitas (ÁVILA, 2000, s.p.).

Apesar de ter dado largos passos rumo à "politização da esfera privada", a conquista desse espaço ainda é um desafio para as mulheres, uma vez que: "a esfera pública tanto na dimensão do Estado, como em outros planos, onde também se processam os conflitos políticos, ainda se constitui como um espaço social onde as desigualdades de gênero, de classe e de raça estão presentes" (ÁVILA, 2001, p. 17).

Entre as dificuldades enfrentadas pela população feminina em ascender à cena política, está a necessidade de romper com a construção histórica que coloca a casa, o lar e a família como únicos espaços possíveis para a existência cotidiana das mulheres. E é nesse ponto que Ávila (2001) chama atenção para a importância de analisar o patriarcado em meio ao momento histórico em que ele se apresenta:

[...]. Reconhecer a existência desse sistema de dominação e fazer conhecer os mecanismos de sua reprodução em qualquer medida que isso ainda aconteça é uma importante contribuição do feminismo para a democratização da vida social. Não levar em conta a questão do patriarcado coloca, por outro lado, um limite na concepção e nas estratégias de luta por igualdade (ÁVILA, 2000, s.p.).

Ao expor os enlaces entre o sexismo, o patriarcado e o capitalismo, os estudos de gênero, ao longo dos últimos 20 anos, têm se convertido como um dos campos mais explorados pela Economia Política da Comunicação, uma vez que, como bem assinala Janet Wasko (2006), tal corrente teórica se preocupa em problematizar as relações de poder que movem as engrenagens dos grupos de mídia. "(...) A economia política da comunicação está interessada, 


\section{Obevisto}

ISSN n² 2447-4266

Vol. 3, n. 1, Janeiro-Março. 2017

DOI: http://dx.doi.org/10.20873/uft.2447-4266.2017v3n1p58

principalmente, no estudo da comunicação e dos media como bens produzidos por indústrias capitalistas" (WASKO, 2006, p. 33).

Nesse sentido, o quadro teórico-metodológico da economia política feminista desponta como importante recurso quando da análise da inserção das mulheres nesse lócus, por revelar tendências investigativas em torno da presença delas nas coberturas de pautas relacionadas às suas causas. Desse modo, "(...) a meta para a economia política é determinar a melhor forma de teorizar os gêneros dentro de uma análise política, econômica, ou seja, para sugerir áreas de compreensão e, quando essa não é possível, para identificar termos ou zonas de engajamento" (MOSCO, 2010, p. 1996).

Dialogando com Vincent Mosco (2010), Carolyn M. Byerly e Karen Ross (2006) revelam que, quando teorizamos acerca da posição das mulheres nas indústrias culturais, devemos pesquisar, dentre outros aspectos, as microestruturas: se os conteúdos produzidos pelos grupos de mídia analisam a representação delas como sujeitos promotores dos seus direitos humanos. É preciso, ainda, segundo Ellen Riordan (2004), examinar o lugar ocupado pelas mulheres - como produtoras, fontes e "protagonistas" - nos processos sociais alimentados por relações - inclusive subjetivas - entre o capitalismo e o patriarcado. "Além de oferecer uma crítica do nível de macroestruturas sociais, economia política feminista salienta a importância das questões de compreensão da identidade, a subjetividade, prazer e consumo, bem como do trabalho visível e invisível no dia-a-dia da vida das mulheres" (RIORDAN, 2004: 85).

\section{Os percursos metodológicos}

O mergulho na Análise de Conteúdo e a realização de um levantamento bibliográfico sobre imagem da mulher na mídia foram estratégias operativas 


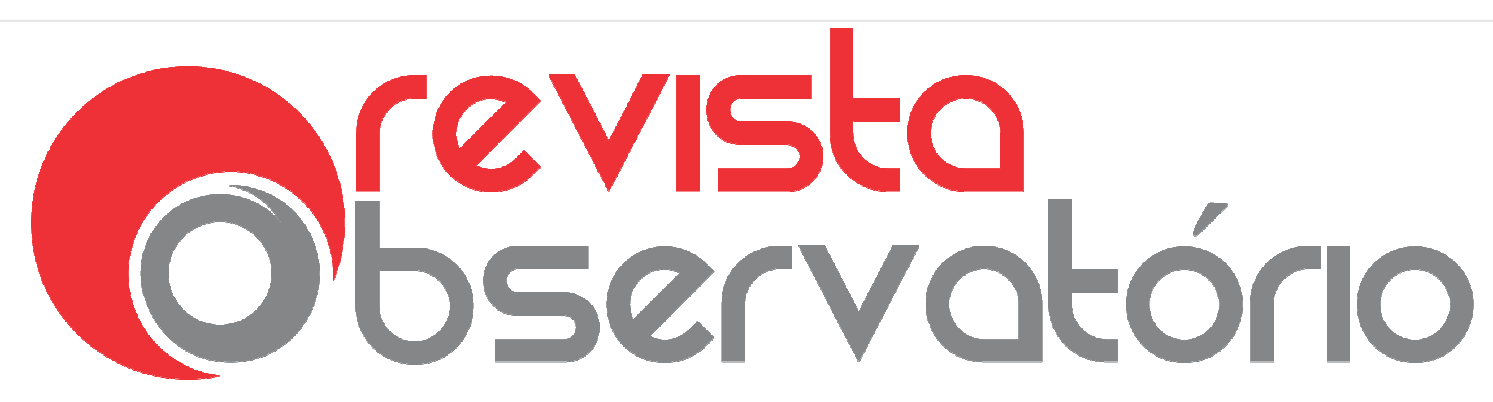

ISSN n² 2447-4266

Vol. 3, n. 1, Janeiro-Março. 2017

DOI: http://dx.doi.org/10.20873/uft.2447-4266.2017v3n1p58

quando da análise das duas matérias que compõem o corpus do presente artigo. No entanto, o estudo também levou em consideração as conclusões de outros trabalhos sobre a influência da mídia no debate público com recurso à teoria do agendamento, haja vista o poder dos meios de comunicação no engendramento do real e da vida em sociedade. A pesquisa também teve como base produções que discutem a posição que as relações de gênero ocupam nos conteúdos publicados pelos meios de comunicação.

A análise empreendida nesse estudo é essencialmente qualitativa, tendo em vista que a mesma avalia o conteúdo nem sempre imediatamente percebido e o "sentido geral dos textos, do contexto onde aparece, dos meios que o veiculam e/ou dos públicos aos quais se destina" (HERSCOVITZ, 2010, p. 127). Sendo assim, faz-se uso da Análise de Conteúdo (AC), que se apresenta como método eficaz para a análise do corpus desse estudo, uma vez que a mesma objetiva, segundo Antonio Chizzotti, "compreender criticamente o sentido das comunicações, seu conteúdo manifesto ou latente, as significações explícitas ou ocultas" (CHIZZOTTI, 2006, p. 98). De maneira descritiva, Heloiza Golbspan Herscovitz define a análise de conteúdo jornalística como

\footnotetext{
[..] método de pesquisa que recolhe e analisa textos, sons, símbolos e imagens impressas, gravadas ou veiculadas em forma eletrônica ou digital encontrados na mídia a partir de uma amostra aleatória ou não dos objetos estudados com o objetivo de fazer inferências sobre seus conteúdos e formatos enquadrando-os em categorias previamente testadas, mutuamente exclusivas e passíveis de replicação (HERSCOVITZ, 2010, p. 126-127).
}

Apesar de suas primeiras definições enfatizarem uma dimensão quantitativa, herdada do positivismo (HERSCOVITZ, 2010), a AC atingiu novas possibilidades com a incorporação de uma exploração qualitativa de mensagens e informações, sobretudo com a diversificação das pesquisas 


\title{
Observatório
}

ISSN n² 2447-4266

Vol. 3, n. 1, Janeiro-Março. 2017

DOI: http://dx.doi.org/10.20873/uft.2447-4266.2017v3n1p58

científicas. A integração de um viés qualitativo vai de encontro à ideia de que a AC é uma técnica de pesquisa para descrição objetiva, sistemática e apenas quantitativa do material analisado.

Nessa perspectiva, Martin Bauer (2003) aponta que a análise de texto "faz uma ponte entre um formalismo estatístico e a análise qualitativa dos materiais. No divisor quantidade/qualidade das ciências sociais, a análise de conteúdo é uma técnica híbrida que pode mediar esta improdutiva discussão sobre virtudes e métodos" (BAUER, 2003, p. 190).

Ainda no que se refere ao objeto de estudo desse artigo, as análises acerca das estruturas ideológicas que movimentam as indústrias da comunicação e as reflexões sobre importância da atuação feminina nesse lócus ressaltam a imprescindível realização de estudos de cunho qualitativo que problematizem a relação das mulheres com os grupos de mídia, em meio ao contexto econômico, simbólico e cultural, como alerta Michèle Mattelart:

\begin{abstract}
Há uma tendência em analisar o assunto mulher e mídia de maneira isolada e fragmentada, como se tanto a análise dessa relação como a resposta e a formulação de propostas destinadas a modificá-la pudessem se desenvolver sem levar em consideração a totalidade social, ou seja, todo o intrigante sistema social com características de relacionamento e dinâmicas próprias. A articulação com a totalidade social nos leva, antes de abordar o tema, a tentar definir, em termos muito gerais, o papel das indústrias culturais e dos aparelhos de comunicação e de cultura de massa e como se vinculam com a sociedade, além de recordar, muito brevemente, o lugar e o papel das mulheres nesta mesma sociedade ${ }^{5}$ (MATTELART, 1982, p. 5).
\end{abstract}

Dessa maneira, estudos com tais características, como o que analisa as produções das revistas Veja e IstoÉ, podem espelhar tendências e ajudar na caracterização das relações entre homens e mulheres no campo onde as indústrias culturais estão se desenvolvendo.

\footnotetext{
${ }^{5}$ Tradução livre das autoras.
} 


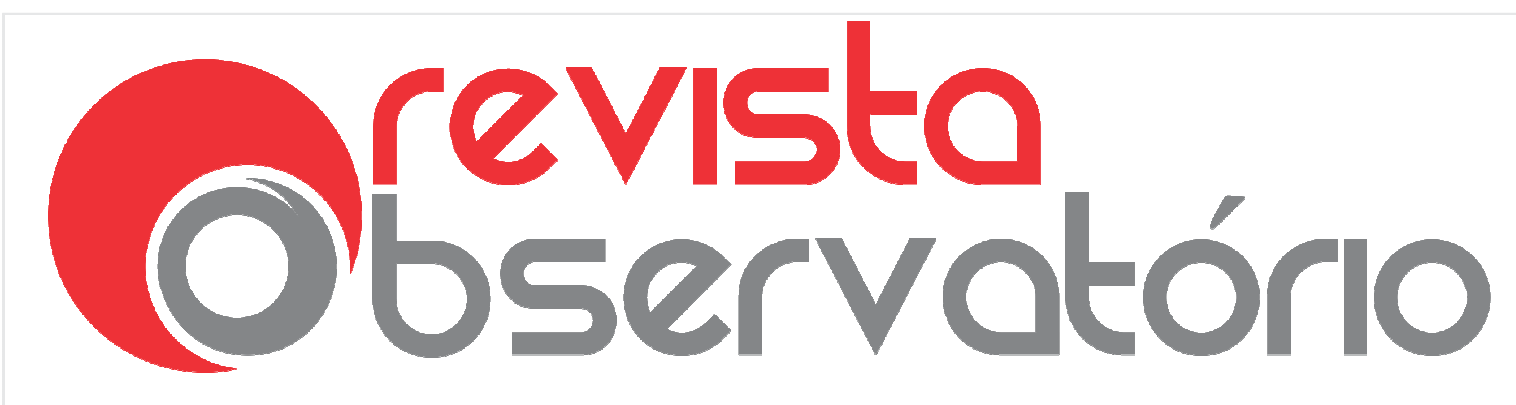

ISSN n² 2447-4266

Vol. 3, n. 1, Janeiro-Março. 2017

DOI: http://dx.doi.org/10.20873/uft.2447-4266.2017v3n1p58

\section{Os rastros do machismo na "Bela, Recatada e do Lar"}

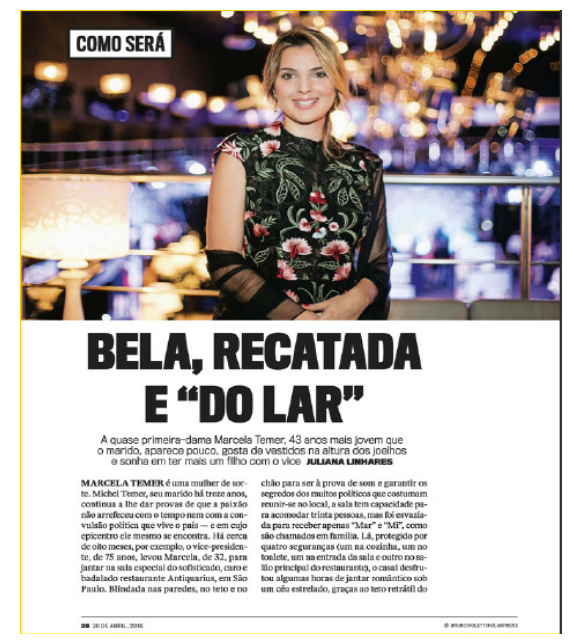

Figura 1: Página que abre a matéria da Veja. Edição Extra, 18 de abril de 2016.

Para muitos/as pesquisadores/as, os veículos de comunicação fixam estereótipos geradores de preconceitos e discriminação, produzindo e reproduzindo valores e hábitos consoantes a formações ideológicas sexistas. A mídia reforça um modelo de superwoman, isto é, da mulher que está inserida no mercado de trabalho, que cuida dos/as filhos/as, do marido e da casa, e ainda está sempre arrumada, corroborando modelos de beleza calcados na feminilidade e na juventude. Para Rachel Moreno:

A mídia comanda, sem mandar. Mandam a mulher ser bela, ser magra, ser boba, ser mãe, ser invejosa, competir com as outras, manda correr em busca da felicidade perfeita que virá a partir da compra de produtos e valores, da exibição de marcas e etiquetas que nos identifiquem e qualifiquem. Sem tom de mando, a mídia evita a resistência e a rebelião (MORENO, 2009, p. 13). 


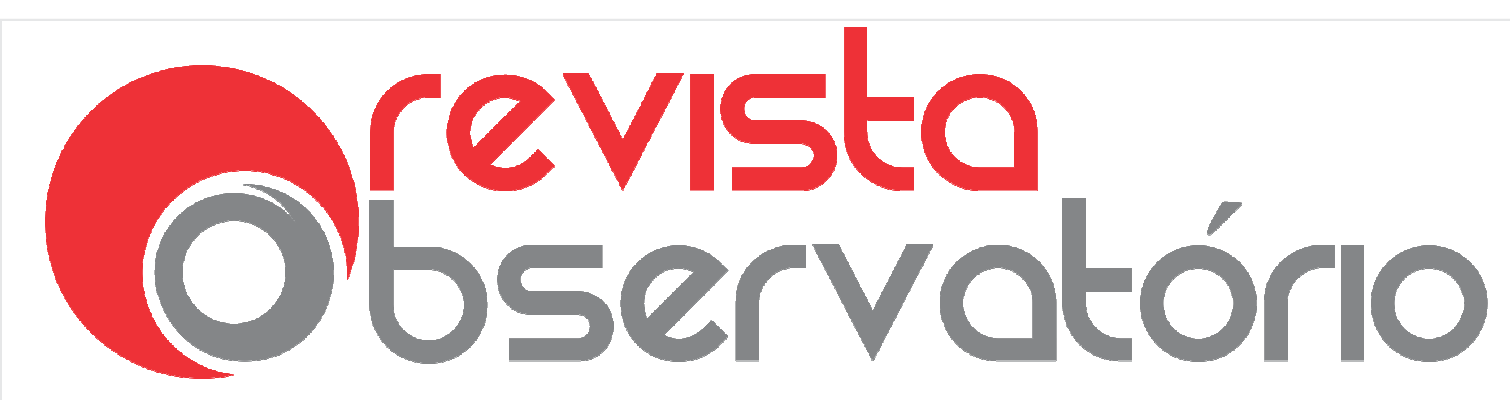

ISSN n² 2447-4266

Vol. 3, n. 1, Janeiro-Março. 2017

DOI: http://dx.doi.org/10.20873/uft.2447-4266.2017v3n1p58

A exemplo do que foi elencado por Rachel Moreno, podemos citar uma das reportagens da revista Veja, publicada na Edição Extra sobre o impeachment, em 18/04/16 $6^{6}$ objeto de análise desse artigo. Intitulada Bela, recatada e "do lar", a matéria, assinada pela jornalista Juliana Linhares, destinase a traçar um perfil da então vice-primeira-dama do Brasil, Marcela Temer, descrita como uma mulher " 43 anos mais jovem que o marido, aparece pouco, gosta de vestidos na altura dos joelhos e sonha em ter mais um filho com o vice" (LINHARES, 2016).

Ao longo de cinco parágrafos, o texto evidencia as qualidades de Marcela ao exercer seu papel de mãe e esposa dedicada, reforçando estereótipos da maternidade plena e da beleza feminina, o que colabora com um dos problemas centrais da relação mulher e mídia: a necessidade de evidenciar aspectos que reeditem modelos femininos consagrados pelo patriarcado. A matéria reproduz, ainda, o mito da maternidade compulsória, como uma sina comum para todas as mulheres, da qual, "naturalmente", Marcela Temer não poderia abdicar. Dessa maneira:

a maternidade, uma função orgânica, é promovida em termos simbólicos a um nível identitário, essencial, portadora de um destino social ancorado no corpo. Objetiva-se, desta forma, a imanência que faz das mulheres este corpo fractal: é a apropriação social do corpo construído em mulher que confere a todas as mulheres um destino biológico, quase uma fatalidade (NAVARRO-SWAIN, 2007, p. 205).

No que se refere à sexualidade e à reprodução, Mercedes Lima (2009) afirma que a maternidade, em especial na teledramaturgia, ainda é colocada como uma imposição. Personagens têm sua valorização a partir de sua capacidade reprodutiva: o fato de não poder ou não querer ser mãe influirá

\footnotetext{
${ }^{6}$ Embora a data da publicação seja 18 de abril, a reportagem entrou em circulação no sábado, 16 de abril, um dia antes da votação do impeachment na Câmara dos Deputados.
} 


\section{Observisto}

ISSN n² 2447-4266

Vol. 3, n. 1, Janeiro-Março. 2017

DOI: http://dx.doi.org/10.20873/uft.2447-4266.2017v3n1p58

negativamente em suas vidas. "Ainda é comum a louvação da heroína da novela, como cuidadora (dos filhos, do marido/companheiro, dos doentes, da casa), ignorando-se sua sexualidade" (LIMA, 2009, p. 28).

E esse ideal de maternidade compulsória ultrapassa as telas da dramaturgia televisiva e se estende também à imprensa tradicional. Ao relatar a vida de Marcela Temer, a reportagem da Veja realça seu papel de mãe, esposa e mulher exemplar. "Marcela é uma vice-primeira-dama do lar. Seus dias consistem em levar e trazer Michelzinho da escola, cuidar da casa, em São Paulo, e um pouco dela mesma também" (LINHARES, 2016, p. 29). Em outro trecho, permanece o destaque sobre a maternidade:

No fim do ano passado, Marcela pensou que esperava o segundo filho, mas foi um alarme falso. "No final, eles acharam que não teria sido mesmo um bom momento para ela engravidar, dada a confusão no país", conta tia Nina, irmã da mãe de Marcela. Ela se refez do sobressalto, mas não se resignou - ainda quer ter uma menininha (LINHARES, 2016, p. 29).

A utilização do termo sobressalto e do verbo resignar confere uma importância maior à maternidade de Marcela. Ao afirmar que a mesma "não se resignou" diante do alarme falso de uma gestação, o texto coloca a maternidade em primeiro plano na vida da vice-primeira-dama: aquela que não desistiu de engravidar novamente. Tais ideais, valorizados por uma parcela da nossa sociedade que ainda persiste em relegar às mulheres uma posição de subalternidade social, perpassam a narrativa construída sobre Marcela Temer.

Vale ressaltar, no caso analisado, o fato de que, mesmo depois de séculos de lutas feministas interseccionais e plurais para a ascensão das mulheres à esfera pública, a revista Veja ainda hipervaloriza a reprodução de um padrão comportamental feminino relacionado com o ambiente doméstico. No Brasil, os movimentos feministas interseccionais e plurais contestam, há 


\section{Observatório}

ISSN n² 2447-4266

Vol. 3, n. 1, Janeiro-Março. 2017

DOI: http://dx.doi.org/10.20873/uft.2447-4266.2017v3n1p58

vários anos, a invisibilidade da mulher, a mercantilização do seu corpo e a reprodução do estereótipo feminino "como naturalmente vinculado ao lar", valorizado pela mídia. Tudo isso, segundo o próprio movimento, busca fundamentar a dupla jornada e a opção, pelas mulheres, em abrir mão de lutar pelos mesmos espaços no campo profissional.

Estudiosas dos movimentos feministas, tais como Mercedes Lima (2009), Rachel Moreno (2009; 2012), Vera Vieria (2007), Dafne Plou (2007), entre outras, apontam, ainda, a ausência de protagonismo das mulheres enquanto fontes nos veículos de comunicação como um dos sintomas da subordinação delas ao gênero masculino. Para Lima (2009), "os conceitos e a visão sobre a mulher veiculados na mídia e na grade de programação de TV (...) reforçam a situação hierárquica entre homens e mulheres, a partir de uma determinada visão de mundo, levando à construção (ou desconstrução) da mulher real" (LIMA, 2009: 27).

A respeito da hierarquização, é possível elencar passagem da matéria aqui analisada: "Marcela é o braço digital do vice. Está constantemente de olho nas redes sociais e mantém o marido informado sobre a temperatura ambiente" (LINHARES, 2016, p. 29). Marcela é aqui descrita como a mulher cuja função é apoiar o marido, atuando em segundo plano e sem protagonismo. Desse modo, sua "identidade discreta" fortalece a do cônjuge, que habita o mundo público, o espaço da política. Enquanto, para ela, resta o ambiente privado como único lugar para quem tem um destino a cumprir, ou mesmo, "encenar" de modo a conquistar reconhecimento social, inclusive por ser portadora de uma beleza comparável, ao menos pela Veja, à da Grace Kelly, considerada uma das atrizes mais bonitas e influentes de Hollywood, ícone de moda e beleza. Grace, princesa de Mônaco, era branca, magra e de cabelos loiros, assim como Marcela. 


\section{Obrevisto}

ISSN n² 2447-4266

Vol. 3, n. 1, Janeiro-Março. 2017

DOI: http://dx.doi.org/10.20873/uft.2447-4266.2017v3n1p58

A comparação com Grace Kelly reforça o ideal de beleza feminina, que estereotipa as mulheres dentro de um determinado padrão excludente, sem abarcar a pluralidade de características de tons de pele - especialmente das mulheres brasileiras/latinas, tipos de cabelo e de corpo, além de não levar em consideração a identificação e a aceitação das mulheres com os corpos que possuem e que são diferentes do modelo exaltado. Essa colocação remonta ao ideal de princesa, que deve estar sempre bela e arrumada à espera de seu príncipe encantado. No entanto, tal beleza deve ser "apresentada" de maneira "discreta":

Em todos esses anos de atuação política do marido, ela apareceu em público pouquíssimas vezes. Marcela sempre chamou atenção pela beleza, mas sempre foi recatada", diz sua irmã mais nova, Fernanda Tedeschi. "Ela gosta de vestidos até os joelhos e cores claras", conta a estilista Martha Medeiros (LINHARES, 2016, p. 29).

Além da matéria sobre Marcela Temer, e levando em consideração que o presente texto visa analisar o tratamento dispensado pela Veja e pela IstoÉ no enquadramento da agora primeira-dama e da agora presidenta deposta Dilma Rousseff no contexto do impeachment, faz-se necessário apontar algumas características relacionadas à edição da revista da editora Abril na qual a matéria foi publicada. A Veja, que possui periodicidade semanal e publica nova edição às quartas-feiras, veiculou uma edição especial sobre o impeachment de Dilma um dia após a votação na Câmara dos Deputados - 18 de abril de 2016, uma segunda-feira. Ao longo das 52 páginas da edição, Marcela Temer e Dilma Rousseff são as únicas mulheres na narrativa elaborada pela revista, que apresentou as duas de forma dicotômica: enquanto a vice-primeira-dama foi retratada sob o estereótipo da beleza e enquadrada no ambiente doméstico, a então presidenta da República foi retratada como uma mulher histérica e despreparada para ocupar o mais alto cargo do poder Executivo brasileiro. 


\section{Obrevisto}

ISSN n² 2447-4266

Vol. 3, n. 1, Janeiro-Março. 2017

DOI: http://dx.doi.org/10.20873/uft.2447-4266.2017v3n1p58

Apesar de a matéria sobre Marcela Temer funcionar como um contraponto à imagem de Dilma, evidenciando um ideal de beleza e comportamento, os enquadramentos das duas personagens possuem um ponto de intersecção no que se refere à imagem da mulher na mídia: a desqualificação da figura feminina promovida pelos meios de comunicação para exercer papéis de destaque na vida pública. Em especial no que concerne ao campo da política, a narrativa midiática ratifica os papeis femininos que, embora diferentes, relegam à mulher um espaço de subalternidade e de menor destaque. No caso espećífico da revista Veja, a narrativa relega à Dilma o papel de mulher emocionalmente descontrolada e incompetente para a política; e à Marcela a função de apoiar o marido, cuidando da casa e da família e trabalhando para que seu mandato ocorra bem.

Sobre o enquadramento referente à Marcela, além da matéria em si, é possível perceber a reafirmação de papel pela organização da edição: o perfil sobre a então vice-primeira-dama é publicado logo após duas matérias sobre Michel Temer, intituladas $A$ hora e a vez do Vice (BONIN, 2016, p. 23) e Tudo a favor de Temer (COUTINHO, 2016, p. 26). Na narrativa elaborada pela revista, o então vice-presidente é apresentado como a estrela principal que "não terá o direito de errar e promete o fim das mágicas na economia" (BONIN, 2016: 23). Para isso, tem a seu favor várias circunstâncias, dentre elas uma esposa "bela, recatada e do lar" e que é seu "braço digital" (LINHARES, 2016: 29).

\section{Quando Dilma Rousseff é desqualificada pela IstoÉ}

Afastada da Presidência da República, Dilma Rousseff foi personagem central da mídia brasileira - e internacional -, nas semanas que antecederam a 


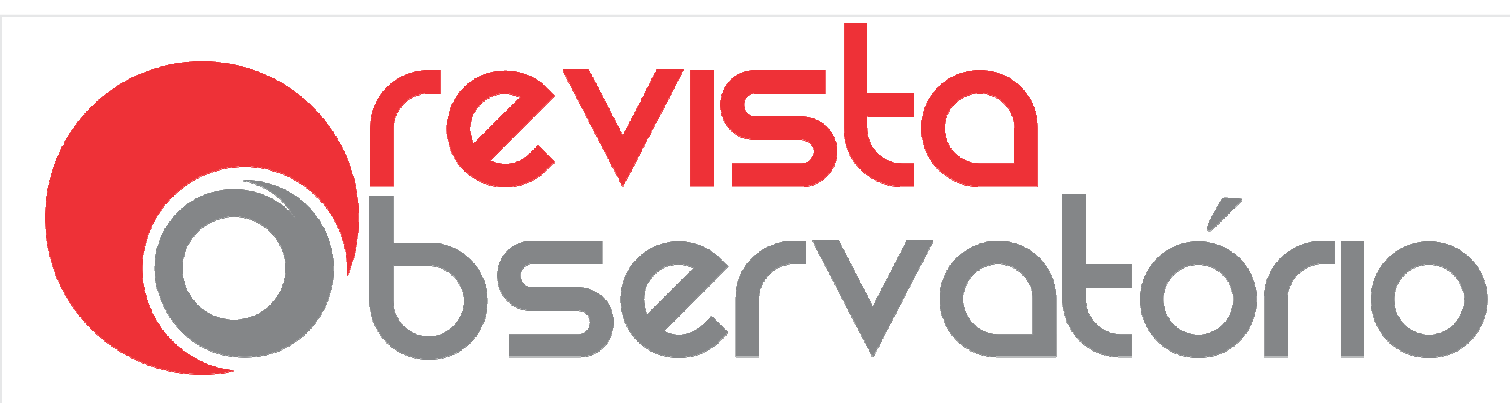

ISSN n² 2447-4266

Vol. 3, n. 1, Janeiro-Março. 2017

DOI: http://dx.doi.org/10.20873/uft.2447-4266.2017v3n1p58

votação do processo de impeachment, aprovado pela Câmara Federal em abril de 2016, e ratificado no Senado, em agosto de 2016. Ela ocupou grande parte do noticiário televisivo, radiofônico e impresso, com direito, inclusive, a sucessivas capas de revistas semanais como Veja, IstoÉ, Época e Carta Capital, como é o caso da edição da IstoÉ, de 6 de abril, objeto de análise desse artigo. A publicação traz, em sua manchete, o título: "As explosões nervosas da presidente", ilustrada com uma foto de Dilma com uma expressão histérica, como induz a figura 2.

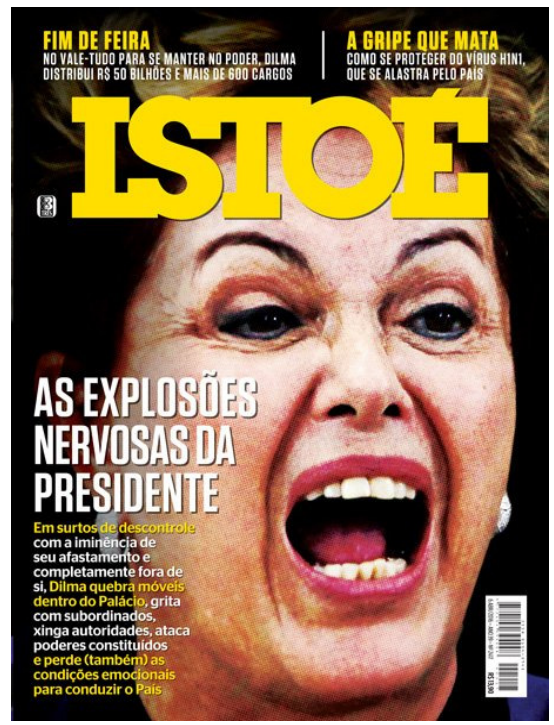

Figura 2: Capa da revista IstoÉ. Edição n 2417, de 6 de abril de 2016.

Observando a imagem, a impressão que se tem é de uma mulher desequilibrada, fazendo jus à manchete da revista. Diante da grande repercussão que tal edição teve, sobretudo entre os movimentos feministas e nas redes sociais, veio à tona que a foto que estampava a capa da revista foi tirada no momento em que Dilma torcia para a seleção brasileira de futebol masculino durante um jogo da Copa das Confederações, em 2013. 


\section{Observotório \\ ISSN n² 2447-4266 \\ Vol. 3, n. 1, Janeiro-Março. 2017 \\ DOI: http://dx.doi.org/10.20873/uft.2447-4266.2017v3n1p58}

A pesquisadora Jeana Laura da Cunha Santos estudou o tratamento que a mídia deu à imagem de Dilma Rousseff nas edições que antecederam a votação do impeachment. Ela, que analisou, inclusive, os recursos fotográficos utilizados pelos veículos de comunicação, percebe os traços da ideologia dos grupos de mídia expressos nas produções.

Com recursos de fotomontagem ou foto em perspectiva, o jornalismo praticado pelos meios hegemônicos constrói sentidos e revela seu caráter ideológico perverso. (...) Tais fotos em perspectiva, atraentes pelo jogo inusitado e jocoso que contêm, trazem em si o reflexo sociocultural, econômico e político de quem a realiza ou a veicula, convertendo-se assim num aparelho reprodutor de ideologia. Descaracterizando a realidade, sem propriamente inventá-la, revelam a primazia da estética sobre a ética, quando não raro abandonam a ética para ficar com a pilhéria (SANTOS, 2016, s.p.).

Para Jeana Santos, as abordagens retratam um tom preconceituoso com uma presidenta mulher, a primeira da história do Brasil. "Uma das formas assumidas pela misoginia é o ato de ridicularizar uma mulher, tornando seu corpo e/ou ações risíveis" (SANTOS, 2016: s.p.). Ainda segundo a pesquisadora, distorcer os fatos é uma prática antiga da mídia.

Cortes, manipulações, edições distorcidas de imagens, e até montagens, sempre estiverem presentes no fotojornalismo brasileiro e muitas vezes serviram para driblar a censura de alguns governos. (...) em algumas situações estão a serviço do preconceito, da desinformação (SANTOS, 2016, s.p.).

Ao longo de oito páginas, a revista IstoÉ traz relatos de supostos episódios vexatórios, nenhum deles com fontes identificadas, que acusam a presidenta de ter vivido momentos de surto. Em artigo publicado no site da Carta Capital, a editora executiva do veículo, Clarice Cardoso, classifica a edição da IstoÉ como sexista e critica a falta de fontes qualificadas, as quais chama de fontes apócrifas, que colocam em xeque a credibilidade da reportagem: 


\section{Obsevisto \\ ISSN n² 2447-4266 \\ Vol. 3, n. 1, Janeiro-Março. 2017 \\ DOI: http://dx.doi.org/10.20873/uft.2447-4266.2017v3n1p58 \\ A mais minuciosa das leituras terá dificuldade em encontrar um parágrafo com argumentação que possa ser levada a sério, denúncia devidamente apurada ou fonte de informações que tire o artigo da categoria dos mexericos. O que há são frases de pretensa ironia que resvalam sem pudor no preconceito de gênero (CARDOSO, 2016, s.p.).}

Na reportagem, cujo título é Uma presidente fora de si, a IstoÉ elenca uma série de frases supostamente disparadas por Dilma, relatando episódios em que ela teria ofendido ministros, assessores e funcionários próximos, sem, no entanto, apresentar consistência nas acusações, nem sequer ouvir tais pessoas apontadas. Exemplo disso é o trecho "você está maluco? Vai se f...! É a presidente que está aqui (no avião). O que está acontecendo?" (PARDELLAS; BERGAMASCO, 2016, p. 35), citação atribuída, pela revista, à presidenta Dilma, ao se referir ao piloto, em um momento de turbulência a bordo do avião presidencial. Ou "cale sua boca. Você não entende disso. Só fala besteira" (PARDELLAS; BERGAMASCO, 2016, p. 35), expressão também atribuída à Dilma, em discussão com a então ministra dos Direitos Humanos, Maria do Rosário.

Nem no episódio do piloto nem no da ministra, a reportagem da IstoÉ, cujos autores são os repórteres Sérgio Pardellas e Débora Bergamasco, ouviu os envolvidos, nem mesmo a presidenta Dilma. O que Clarice Cardoso chama de fontes apócrifas e mexericos são os recursos usados pelos jornalistas na construção do texto, sempre recorrendo a termos como "segundo testemunho de um integrante do primeiro escalão do governo" (PARDELLAS; BERGAMASCO, 2016, p. 34), "segundo relatos" (PARDELLAS; BERGAMASCO, 2016, p. 34), ou "um de seus assessores" (PARDELLAS; BERGAMASCO, 2016, p. 36), sem identificar as fontes para justificar a informação.

As observações de Clarice Cardoso convergem com o que defende Juarez Bahia (2009), autor do livro Jornal, História e Técnica: as técnicas do jornalismo. Na obra, ele lembra do cuidado que deve existir durante o processo 


\section{Obrevisto \\ ISSN n² 2447-4266 \\ Vol. 3, n. 1, Janeiro-Março. 2017 \\ DOI: http://dx.doi.org/10.20873/uft.2447-4266.2017v3n1p58}

de apuração jornalística, e ressalta que a credibilidade do texto depende da idoneidade da fonte.

Grande parte da credibilidade de um jornalista ou de um veículo repousa no uso que ele faz das suas fontes na elaboração das notícias. Quanto mais responsável e transparente for, mais próximo da objetividade estará. Utilizar o anonimato da fonte para embutir a opinião pessoal ou para abrigar interesse escuso é uma frontal violação da ética profissional (BAHIA, 2009, p. 45).

Principal personagem da reportagem, a presidenta Dilma não foi ouvida em nenhum momento. As aspas que são creditadas a ela partem de terceiros, de boatos, tudo sempre com uma introdução do tipo "segundo alguém". Além desse problema letal da falta de credibilidade das fontes de informação, outra questão que coloca em cheque a seriedade da reportagem é a adjetivação do texto, o excesso de opinião e a falta de respeito para com o cargo máximo de um país, a Presidência da República, o qual é desmoralizado na narrativa, indicando, inclusive, a defesa do impeachment, tanto na reportagem como no editorial da mesma edição.

Eis alguns trechos dessa narrativa: "(...) Dilma Rousseff perdeu também as condições emocionais para conduzir o país"; "(...) dispara palavrões aos borbotões a cada e frequente má notícia" (PARDELLAS; BERGAMASCO, 2016, p.34).

(...) nas últimas duas semanas, a presidente desmantelou-se emocionalmente. Um governante, ou mesmo um líder, é colocado à prova exatamente nas crises. $E$, hoje, ela não é nem uma coisa nem outra. (...) Os surtos, os seguidos destemperos e a negação da realidade revelam uma presidente completamente fora do eixo e incapaz de gerir o País (PARDELLAS; BERGAMASCO, 2016, p. 37).

A desqualificação da figura de Dilma Roussef pelos veículos de comunicação reflete uma cultura de violência simbólica sofrida pelas mulheres 


\section{Obrevisto}

ISSN n² 2447-4266

Vol. 3, n. 1, Janeiro-Março. 2017

DOI: http://dx.doi.org/10.20873/uft.2447-4266.2017v3n1p58

no campo das narrativas midiáticas. Em especial no que se refere à arena política, mulheres que participam de maneira ativa são, muitas vezes, diminuídas e postas à prova. Os fatos aqui elencados expõem o difícil quadro de machismo que permeia a sociedade brasileira e que aflora tanto no campo da atuação política das mulheres, quanto na cobertura realizada pelos grupos de mídia. Isso demonstra o quanto a imprensa brasileira estereotipa a mulher e contribui para a reprodução de uma cultura de misoginia.

\section{Considerações finais}

Se cada vez mais a própria história é reproduzida e produzida com o acesso da sociedade aos meios de comunicação, cabe, então, investir na realização de pesquisas que aportem elementos que ajudem a revelar a complexa teia de relações sociais em torno da presença das mulheres nas indústrias culturais. Nesse sentido, as reportagens elaboradas por revistas de notícias com periodicidade semanal, como é o caso da IstoÉ e da Veja, deveriam prioritariamente ser pautadas por fatos dos contextos social, político e econômico vigentes no momento da produção e da veiculação da notícia.

A forma como a presidenta deposta tem sido retratada por diversos meios de comunicação - não só nas reportagens acerca do impeachment, mas durante todo o seu governo - tem sido fruto de um jornalismo alicerçado em meio à expansão do modo de produção capitalista em uma sociedade historicamente patriarcal. Essa superexposição de forma desqualificada levou a própria Dilma Rousseff a reconhecer que estava sofrendo discriminação, tanto no campo político, quanto no midiático, também pelo fato de ser mulher. 


\section{Obevisto}

ISSN n² 2447-4266

Vol. 3, n. 1, Janeiro-Março. 2017

DOI: http://dx.doi.org/10.20873/uft.2447-4266.2017v3n1p58

Contudo, essa realidade vem mudando lentamente pela ação dos movimentos feministas, sobretudo a partir dos anos de 1970, quando suas militantes exigiram mais espaço na sociedade, maior presença no mercado de trabalho e autonomia sobre suas vidas. Apesar disso, ainda são muitas as formas de discriminação e violência sofridas pelas mulheres, e as representações do feminino feitas a partir da mídia seguem essa tendência.

Além disso, a matéria que mereceu a principal chamada de capa da revista IstoÉ na edição de 6 de abril de 2016 tenta pautar no debate público brasileiro que a então presidenta Dilma Rousseff não tinha condições emocionais e políticas para continuar seu mandato. Agindo dessa forma, o periódico mostra a fragilidade da mídia brasileira, que, em muitos momentos, abdica do papel de comunicar para agir tal qual partido político, como bem defendeu, em 2010, Maria Judith Brito, então presidenta da Associação Nacional de Jornais (ANJ) e executiva do grupo Folha de S. Paulo: "os meios de comunicação estão fazendo de fato a posição oposicionista deste país, já que a oposição está profundamente fragilizada. E esse papel de oposição, de investigação, sem dúvida nenhuma incomoda sobremaneira o governo" (BRITO apud ARAÚJO, 2010: s.p.).

Já a reportagem da Veja, sobre Marcela Temer, esposa do então vicepresidente Michel Temer quando da publicação, pode ser concebida como exacerbação de uma "receita de sucesso", ou mesmo a exaltação de um aspecto da condição feminina que naturaliza a subalternidade até com certo glamour, uma vez que expõe faces do cotidiano da mulher de um dos personagens mais importantes no Brasil, no momento. Contudo, o texto deixa de problematizar tal naturalização, o que poderia ter oferecido, aos seus/suas leitores/as, um cardápio eclético acerca do que pode vir a "ser mulher" em nossa sociedade. 


\section{Obrevisto}

ISSN n² 2447-4266

Vol. 3, n. 1, Janeiro-Março. 2017

DOI: http://dx.doi.org/10.20873/uft.2447-4266.2017v3n1p58

É importante destacar que a matéria Bela, Recatada e "do Lar" foi veiculada em um momento no qual a exaltação da família tradicional está em voga: a veiculação do texto no site da revista Veja se deu no final de semana da votação na Câmara dos Deputados sobre o processo de impeachment da presidenta Dilma Rousseff, no qual diversos parlamentares alegaram votar "em nome de Deus e de suas esposas, filhos e demais parentes," na sessão realizada no domingo 17 de abril de 2016.

Ressaltamos aqui que não é possivel afirmar que a matéria sobre a viceprimeira-dama tenha sido pensada sob o escopo da votação, e nem poderia, tendo em vista que o processo de entrevista e coleta de informações com as cincos fontes elencadas no texto demanda tempo, apesar das facilidades de apuração pela internet e por telefone. Entretanto, ressaltamos que sua veiculação nesse contexto de crise política evidencia o modelo de mulher socialmente aceita na política. Algo que Dilma Rousseff nunca foi, ao menos na opinião estampada no texto da IstoÉ.

Contudo, as duas revistas talvez não contassem com a capacidade de mobilização de diversos/as leitores/as que acessaram as redes sociais para problematizar o papel da mídia no Brasil e visibilizar perfis de mulheres que puderam fazer outras escolhas. Aquelas que subverteram a ordem comandada pelos desvalores que imputam sérias restrições ao público feminino. Mulheres que não se enquadram no que os veículos expõem como modelo e que perceberam que os ataques à imagem da presidenta, pela IstoÉ, também acabaram por atingir outras mulheres que não aceitam que tais relações assimétricas de poder e a misoginia venham a ser reproduzidas pelos meios de comunicação. 


\section{Observisto \\ ISSN n² 2447-4266 \\ Vol. 3, n. 1, Janeiro-Março. 2017 \\ DOI: http://dx.doi.org/10.20873/uft.2447-4266.2017v3n1p58}

\section{Referências}

ARAÚJO, Washington. A imprensa como partido político. In.: Observatório da Imprensa, ed. 586, 20 abr 2010. Disponível em < http://observatoriodaimprensa.com.br/armazem-literario/a-imprensa-como-partidopolitico/ > Acesso em 22 mai 2016, às 18h.

ARENDT, Hannah. A Condição Humana. Rio de Janeiro: Forense - Universitária, 1988.

ÁVILA, Maria Betânia. Feminismo e Sujeito Político in: Revista Proposta, n 84-85. Rio de Janeiro: Fase, Mar.-1go., 2000. Disponível em< http://appsindicato.org.br/index.php/?p=14039/ >Acesso em 22 abr 2016, às 22h.

ÁVILA, Maria Betânia et al. Textos e Imagens do Feminismo: mulheres construindo a igualdade. Recife, SOS Corpo, 2001.

BAHIA, Juarez. História, jornal e técnica: as técnicas do jornalismo. vol 2. 5, Rio de Janeiro, Ed. Mauad X, 2009.

BAUER, Martin. Análise de conteúdo clássica: uma revisão. In.: BAUER, Martin; GASKELL, George (ed). Pesquisa qualitativa com texto, imagem e som: um manual prático. 2ed. Ptrópolis: Vozes, 2003, p. 189-217

BONIN, Robson. A hora e a vez do vice. Veja, São Paulo, Edição especial, ano 49, abril de 2016. P. 23-26.

IBOPE MEDIA. Conceitos e Critérios da Pesquisa de Mídia para a Imprensa. Disponível em: <http://www.ibope.com.br/ptbr/relacionamento/imprensa/Documents/cartilha_de_midia .pdf >. Acesso em: 15 out 2015.

CARDOSO, Clarice. Quando a misoginia pauta as críticas ao governo Dilma. Disponível em <http://www.cartacapital.com.br/blogs/midiatico/quando-a-misoginiapauta-as-criticas-ao-governo-dilma >. Acesso em 18 maio 2016, às 22h

CHIZZOTTI, Antonio. Pesquisa em ciências humanas e sociais. 8ed. São Paulo: Cortez, 2006. 


\section{Obrevisto \\ ISSN n² 2447-4266 \\ Vol. 3, n. 1, Janeiro-Março. 2017 \\ DOI: http://dx.doi.org/10.20873/uft.2447-4266.2017v3n1p58}

COUTINHO, Leonardo. Tudo a favor de Temer. Veja, São Paulo, Edição especial, ano 49, abril de 2016. P. 26-27.

FUNDAÇÃO Perseu Abramo. Pesquisa sobre Democratização da Mídia. Disponível em:

http://novo.fpabramo.org.br/sites/default/files/fpa pesquisa democratizacao da midia 0.pdf $>$ Acesso em 22/01/2016, às 16h.

GIL, Antônio. Estudo de caso. São Paulo: Atlas, 2009.

HERSCOVITZ, Heloiza. Análise de conteúdo em jornalismo. In.: LAGO, Claudia; BENETTI, Marcia (orgs). Metodologia de pesquisa em jornalismo. 3 ed. Petrópolis, RJ: Vozes, 2010, p. 123-142.

LINHARES, Juliana. Bela, recatada e "do lar". Veja, São Paulo, Edição especial, ano 49, abril de 2016. P. 28-29.

LIMA, Mercedes. A imagem da mulher na mídia. In: LIMA, Mercedes; VICENTE, Terezinha (Org). O Controle Social da Imagem da Mulher na Mídia. São Paulo: Articulação Mulher e Mídia, 2009, p. 27-31.

MATTELART, Michèle. Mujeres e industrias culturales. Barcelona: Editorial Anagrama, 1982.

MORENO, Rachel. A imagem da mulher na mídia: controle social comparado. São Paulo: Publisher Brasil, 2012.

Vigiar, seduzir, excluir - a colonização das mentes. In. LIMA e VICENTE. $\mathbf{O}$ Controle social da imagem da mulher na mídia. São Paulo: Articulação Mulher e Mídia, 2009, p. 11-16.

MOSCO, Vicent. The Political Economy of Communication. ( $2^{\mathrm{a}}$ ed.). London: Sage Publications, 1996.

NASCIMENTO, Patrícia Ceolin; PRADO, Magaly (org). Técnicas de Redação em Jornalismo: o texto da notícia. São Paulo: Saraiva, 2009. 


\section{Obrevisto \\ ISSN n² 2447-4266 \\ Vol. 3, n. 1, Janeiro-Março. 2017 \\ DOI: http://dx.doi.org/10.20873/uft.2447-4266.2017v3n1p58}

NAVARRO-SWAIN, Tania. "Meu corpo é um útero? Reflexões sobre a procriação e a maternidade". In: STEVENS, Cristina (org.). Maternidade e feminismo: diálogos interdisciplinares. Florianópolis: Ed. Mulheres; Santa Cruz do Sul: Edunisc, 2007.

PARDELLAS, Sérgio; BERGAMASCO, Débora. Uma presidente fora de si. IstoÉ, edição 2417, 06 abr 2016, p. 32-39.

PLOU, Dafne; VIEIRA, Vera. Mulher e tecnologias: a virtualidade como espaço transformador das relações de gênero. São Paulo: Rede Mulher de Educação, 2007.

RAGO, Margareth. Epistemologia feminista, gênero e história. 1998. Disponível em http://www.nutead.uepg.br/gde/downloads/epistemologia_feminista.pdf. Acesso em 15 ago. 2009.

RIORDAN, Ellen; MEEHAN, Eileen R. Sex \& money: feminism and political economy in the media. Minneapolis: University of Minnesota Press, 2002.

RIORDAN, Ellen. The woman Warrior: A feminist political economic analysis of crouching Tiger hidden dragon. I $n$. ROSS, Karen and BYERLY, Carolin M. Women and media. International perspectives. USA: Blackwell Publisshing, 2004, p.81-103.

SANTOS, Jeana Laura da Cunha. O jornalismo contra Dilma: Da misoginia à pirotecnia. Disponível em <http://www.revistaforum.com.br/2016/05/11/o-jornalismocontra-dilma-da-misoginia-a-pirotecnia/ >. Acesso em 18 mai 2016, às $20 \mathrm{~h} 30$.

STAKE. R. E. Case studies. In: DENZIN, N. K.; LINCOLN, Y. S. (ed.) Handbook of qualitative research. London: Sage, 2000. p. 435-454.

UNESCO. Un solo mundo, voces múltiples: comunicación e información en nuestro tiempo. 2 ed. Barcelona, Espanha: 1988.

WASKO, Janet. Estudando a Economia Política dos Media e da Informação. In: SOUZA, Helena (Org). Comunicação, Economia e Poder. Portugal: Porto Editora, 2006, p. 2953. 